\title{
A FORMAÇÃo de SENTIDOS SUBJETIVOS POTENCIALIZADORES DA AMOROSIDADE NO ESPAÇO EDUCACIONAL
}

\author{
THE FORMATION OF SUBJECTIVE SENSES OF LOVELINESS IN \\ SPACE AUGMENTING EDUCATIONAL
}

\author{
Solange Martins Oliveira Magalhães \\ Dra. em Educação, Professora da Graduação e do Programa \\ de Pós-Graduação em Educação - Faculdade de Educaçăo / Universidade Federal de Goiás. \\ Goiás, GO - Brasil. \\ solufg@hotmail.com
}

\begin{abstract}
Resumo: Vivemos tempos em que os sujeitos começam a se reconhecer como seres paradoxais, em processo de recriaçáo constante. $\mathrm{O}$ entendimento de que tudo se liga a tudo, reciprocamente, numa rede relacional e interdependente, tem promovido o entendimento de que o indivíduo é um ser autônomo, mas ao mesmo tempo dependente amorosamente do outro, numa circularidade que o singulariza e distingue simultaneamente. A tecitura de um sujeito nesta perspectiva envolve articular diferentes fios de um processo de humanização que procura equacionar a fragmentação entre razão e emoção, com o objetivo de formar um ser integral portador de novos sentidos subjetivos. Isso passa por um estado de aprendizagens intensificadamente cooperativo, solidário e amoroso. Como ressalva Morin (2002), é necessário desenvolver uma consciência amorosa pensada como parte importante de uma consciência, capaz de ajudar os sujeitos à auto-organizaremse, transformando-se continuamente, estimulando-se a formação de sentidos subjetivos capazes de potencializar a amorosidade no espaço educacional. Essa maneira de conceber o sujeito, concretiza a visão de complexidade defendida por Morin (200I), pois considera as articulações, as interconexôes, as ligaçôes, que materializam aquilo que é tecido junto.
\end{abstract}

Palavras-Chave: Educação. Amorosidade Formação de professores. Transdisciplinaridade.

\begin{abstract}
Aвstract: We live in times when subjects begin to be recognized as being paradoxical, in constant process of recreation. The understanding that everything connects to everything, conversely, a network of relationships and interdependence, has promoted the understanding that the individual is an autonomous being, but at the same time dependent on each other lovingly, a roundness that distinguishes and differentiates simultaneously. The weaving of a subject from this perspective involves articulating different threads of a process of humanization that pass through the formation of subjective meanings that equate mainly the inseparability of the cognitive and affective. It goes through a state of learning intensificadamente cooperative, supportive and loving. As noted by Morin (2002), it is also necessary to develop a loving consciousness conceived as an important part of a heightened awareness that can help the participants (teacher and student) to self-organize themselves, becoming continuously stimulating the formation subjective meanings capable of enhancing the educational space in lovingness and understanding
\end{abstract}


of the real world. This way of conceiving the subject as one who can feel with reflection embodies the vision of complexity advocated by Morin (200I), considering the joints, interconnections, links, substantiating what is woven together.

KeY words: Education. Loving. Teacher training. Transdisciplinarity.

A força do amor é igual à força da alma ou da verdade. (GANDHI, I956, p.236).

A construção de um texto perpassa por nossas experiências e essas se revestem das vivências construídas por algum lugar social, num tempo cultural e histórico. Pelos caminhos percorridos e, em especial, pouco a pouco, gestam-se reflexóes que possibilitam a reformulação de novas sínteses no nosso viver. Esse processo pode nos auxiliar no repensar do novo e, porque náo dizer, assim, como Brandão (2005, p. 37), torna possível o "sentir com reflexão". Entretanto, isso passa necessariamente pela formação de novos e importantes sentidos subjetivos (GONZÁLEZ REY, 2003).

González Rey (2009, p. I30-I3I), compreende os sentidos subjetivos como unidades psíquicas que expressam processos de subjetivação dos sujeitos. Os sentidos subjetivos podem ser definidos como uma representação do que a aprendizagem provoca nos sujeitos, porque nesses sentidos, além de intencionalidade estão presentes as emoçóes. González Rey (2009) conclui que a definiçáo de sentido subjetivo traz novos posicionamentos na compreensão sobre o processo ensino-aprendizagem: primeiro, a aprendizagem é uma produção de sentidos subjetivos e não mais apenas uma operação lógico-formal; segundo, o sujeito aprende envolvido em processos emocionais de forma ativa e efetiva no processo de aprender.

Essa maneira de conceber o sujeito, como "produtor de sentidos que expressam de forma singular, complexos processos da realidade (GONZÁLEZ REY, 2003, prefácio), expressa uma concepção de homem que concretiza a visão de complexidade defendida por Morin (200I), pois se consideram as articulaçôes, as interconexóes, as ligaçōes, que concretizam aquilo que é tecido junto.

Avaliando assim, há muito vimos refletindo sobre o papel do professor na formação de novos profissionais. A formação docente frágil, inicial e continuada, por sua superficialidade traz sérias conseqüências como o empobrecimento de uma das finalidades nobres da educação que é produzir 
nos indivíduos singulares a humanidade. Como afirmou Vygotsky (I998, p. II8) "o aprendizado é um aspecto necessário e universal do processo de desenvolvimento das funçóes psicológicas culturalmente organizadas e especificamente humanas".

Educar é humanizar, essa é uma questão fundamental, pois ela toca nas questóes do que ensinar, a quem ensinar, quando ensinar, como ensinar e por que ensinar, nos levando a entender que todas as áreas do conhecimento, assim como todas as atividades pedagógicas e relaçóes em sala de aula, são fundamentais para formação dos sujeitos.

A concepção complexa de sujeito nos ajuda compreender esse processo. O desenvolvimento da inteligência, da sensibilidade, da criatividade, da afetividade, por exemplo, passa a ser compreendido como parte integrante do processo de desenvolvimento da subjetividade, afetando, no caso de professores, suas formas de pensar, sentir e atuar.

Dessa forma, a formação de sentidos subjetivos não constitui um dom inato, mas produtos das relaçóes histórico-sociais, e por isso mesmo, podem ser ferramentas na promoção de um sujeito melhor (mais humanizado) capaz de um "sentir com reflexão" (BRANDÃO, 2005, p. 37).

Esse processo passa por uma unidade indissociável, por um sistema dialógico e dialético que é, ao mesmo tempo, constituído pelos sujeitos, mas também constituinte e organizador dos mesmos.

Essa ideia é condizente com dois princípios do pensamento da complexidade sugeridos por Morin: o princípio dialógico, que une duas noçôes antagônicas as quais aparentemente deveriam se repetir, mas que são indissociáveis e indispensáveis para a compreensão de uma mesma realidade; e o princípio da recursão organizacional, representado por um círculo gerador, no qual os produtos e os efeitos são eles próprios produtores e causadores daquilo que os produz (SCOZ, 2009 p. 99. Grifos nossos).

Essa ideia assegura que a produção de sentidos representa o núcleo dinâmico da organização da subjetividade. Entretanto, nos cursos de formação de professores, de modo geral, tanto a formação de sentidos subjetivos como a própria subjetividade tem sido negadas no processo formativo, 
a ênfase continua no aspecto cognitivo, excluindo as emoçóes dos sujeitos como elementos formativos.

Neste sentido, torna-se necessário que a formação desenvolvida nos cursos de formação de professores, possibilite as relações entre afetividade e a cognição, ressaltando que os professores são sujeitos complexos em formação. Vislumbramos a possibilidade de formação de sujeitos críticos, capazes de exercitar e confrontar seus pensamentos na formaçáo de novos sentidos subjetivos, que contribuirão para modificaçôes neles mesmos e nos espaços sociais onde atuam.

Soma-se a isso a sinergia que perpassa o trabalho docente, em Freire (2000, p. I60), por exemplo, temos que essa sinergia pode ser expandida para a vida. De acordo com o autor, o educar pode ser "fascinante, comovente", pode possibilitar a admiração e a celebraçáo da vida; pode ajudar o sujeito a ver sua beleza, sua realidade totalmente interconectada, portanto viva e ativa.

Pensando na formação docente, é necessário promover círculos de relacionamentos que permitam a construção de novos sentidos subjetivos, o que nos obriga a levar em consideração a inseparabilidade do cognitivo e do afetivo, do pensamento e das emoçóes na produção do conhecimento.

Para tanto, necessitaríamos estar vivendo num círculo de relacionamento que permitisse a presença de espíritos livres, criativos, libertos da cadeia de comando que assola e conforma nossa educação, "[...] ensinar e aprender não podem dar-se fora da procura, fora da boniteza e da alegria [...] a educação deve ser "estética e ética [...]" (FREIRE, 2000, p. 26).

As palavras de Freire tomam concretude quando cremos que a forma como os sujeitos vão viver a sua realidade e o modo como a transformam liga-se, invariavelmente, à educação. Existe, portanto, a necessidade de um processo formativo que ajude os sujeitos desenvolverem novos sentidos subjetivos que os ajudem a desejarem transformar a realidade.

Infelizmente, uma educação apoiada em um currículo que pensa a formação de maneira disciplinar, dificilmente abrirá espaços para que se possa trabalhar de forma sinergética e para a vida. Reconhecendo-se a importância desses aspectos para a formação humana, a coerência está no entendimento de que podemos ensinar na perspectiva de uma educaçáo para vida; a partir de um sentir com reflexão podemos contribuir com o 
desenvolvimento de um sujeito crítico, epistemologicamente curioso, que constrói o conhecimento ou participa de sua construção.

Segundo Veiga (1989), o docente necessita encarar a educação como um meio de transformação social, com o compromisso de colaborar para a formação de outra realidade social.

Eis aí nosso desafio, aliar o desenvolvimento científico e tecnológico à expansão da consciência, estimulando um processo de autotransformação, desbloqueio de si mesmo, desenvolvimento da autoconsciência elevada, do hábito de solicitar feedback, o que aumentará a sede de aprender, além de consolidar uma forma de educar com dedicação, sensibilidade e, talvez, amor incondicional e desinteressado.

Assim, buscando superar o temor ao novo, ao confronto, pela dificuldade de entrar em contato com algo que constituiu para nós mesmos um novo lugar social, que define este nosso tempo cultural e histórico como tempo de transição, transformação, torna-se urgente um envolvimento direto com um trabalho que visa à formação de novos sentidos subjetivos nos processos de aprender/ensinar.

Como contempla Behrens, isso também passa por desbloquear a visão cartesiana, para superar uma

prática pedagógica fragmentada, revestida de competição, de tratamento austero do docente, de falta de visão da possibilidade de aprender com o erro, cria um clima de instabilidade que não permite aflorar a intuição, a criação, a justiça, a amizade, o compartilhamento, enfim, a sensibilidade necessária ao cidadão (BEHRENS, 2003, p. 70).

Saindo do campo das crenças produtoras de certezas, para participar ativa e criativamente de um movimento que propicie a abertura de espaços facilitadores da formação de novos sentidos subjetivos, propomos novas discussóes que envolvem a tentativa do entendimento da importância da alegria, doação, amorosidade e paixão nos processos formativos.

Entendemos com Freire que não há educação sem amor; educar sem amor pode resultar em uma mera atividade mecânica. Com o autor apreendemos que mais que a própria razão, a condição de amar é que nos torna especiais dentre os seres que habitam a terra, por isso, também temos que 
fazer valer isto no campo da formação docente, é uma parte do belo que há dentro de nós, e pode incentivar práticas pedagógicas criativas, inovadoras na construção de novos sentidos subjetivos.

De González Rey (2003) e Scoz (2009) à Freire (2000) e Morin (2002), parece salutar estarmos irmanados na constituiçáo de uma consciência amorosa, como parte importante de uma consciência ampliada que promove no sujeito a capacidade de auto-eco-organizar-se continuamente, mas há a necessidade da presença do amor, sobretudo nas situaçóes de ensino-aprendizagem, estas podem transformar-se em espaços de ações mutuamente enriquecedoras, no qual ambos (professor e estudante) podem construir novos sentidos subjetivos, co-evoluir e coexistir juntos (MORIN, 2002). Isto também precisa ser ensinado.

\section{Formando novos sentidos subjetivos: auto-eco-organizar-se a partir do entendimento do amor}

Amo como ama o amor. Não conheço nenhuma outra razão para amar senão amar. Que queres que te diga, além de que te amo, se o que quero dizer-te é que te amo? (FERNANDO PESSOA).

Ainda que eu falasse as línguas dos homens e dos anjos, e não tivesse amor, seria como metal que soa ou como o sino que tine. E ainda que eu tivesse o dom de profecia, e conhecesse todos os mistérios e toda a ciência, e ainda que tivesse toda a fé, de maneira tal que transportasse os montes, e não tivesse amor, nada seria (CORÍNTIOS: I3: I-2).

Não constitui novidade pensar que o "amor" é necessário e que está entre nós, entre as pessoas, entre os enamorados, entre pais e filhos, entre amigos. Alguns indicam a sua falta de lógica, como o poeta Brandão (2003, p. 24), “[...] se te escolho é porque já estavas em mim e se amo é porque acordo à noite e sonho que já não sei viver sem ti [...]”; outros ainda negam sua importância indicando que sua presença gera dependência, 
e que o amor nos coloca na encruzilhada do "[...] preciso aprender a ser só. Eu preciso aprender a só ser [...]", como afirma o compositor e poeta Gilberto Gil. Mesmo indicando a sua total falta de lógica ou negando-o, reafirma-se pardoxalmente sua total importância na vida humana.

O poeta português Luís de Camóes, lá no século XVI, descreveu a importância do amor:

Amor é fogo que arde sem se ver/É ferida que dói e não se sente; É um contentamento descontente/É dor que desatina sem doer./É um não querer mais que bem querer/É um andar solitário entre a gente/É nunca contentar-se de contente/É um cuidar que se ganha em se perder./É querer estar preso por vontade/É servir a quem vence o vencedor,/É ter com quem nos mata lealdade./Mas como causar pode seu favor/ Nos coraçôes humanos amizade/Se tão contrário a si é o mesmo amor?

Em Camóes temos o amor como um sentimento essencial, apesar de contraditório, como descrito por Brandão e Gilberto Gil, evidencia-se que o amor é composto harmoniosamente por seus contrários, o que numa lógica complexa e transdisciplinar, pressupóe a manifestação do princípio dialógico proposto pelo pensamento complexo.

A teoria da complexidade procura edificar um método, um caminho, uma estratégia que possibilite construir um conhecimento interpretativo sobre o homem, a sociedade, a educação, suas relaçôes entre si e dessas, com o mundo físico e natural. Estabelece um conjunto de princípios metodológicos que configuram e orientam um pensar complexo: princípio dialógico; princípio de retroatividade; princípio de recursividade; princípio holográfico; princípio da autonomia/dependência (auto-organização), e princípio da reintroduçáo do conhecimento. A premissa é aspirar a um saber não-fragmentado, não-compartimentado, não-redutor, com o reconhecimento do inacabado e da incompletude de qualquer conhecimento (MORIN, 2002).

O "princípio dialógico" é aquele que une complementarmente dois processos ou conceitos antagônicos que deveriam se recusar um ao outro, mas que são indispensáveis e indissociáveis para compreender determinada realidade. Com este princípio, o amor pode unir, assim, noçôes antagônicas, de complementaridade e concorrência entre os elementos que estão em 
processo dialógico, como por exemplo: ordem/desordem, junção/disjunção, universal/específico, razão-emoção, dentre outros. Ao pensar o amor, é o princípio dialógico que possibilita-nos manter a dualidade no seio da unidade ao associar termos, ao mesmo tempo, complementares e antagônicos.

Tal como descreve Brandão (2005, p. 20-26), o amor estabelece conexôes misteriosas, é transformador de sociabilidades; é capaz de renovar, encantar, tornando o existir mais pleno; está presente "[...] na experiência cotidiana da partilha do amor [...]". Seu cultivo é uma grandiosa aventura de reencantamento do mundo e da própria existência, e essas características passam a manifestar a presença do princípio da recursividade.

O "princípio da recursividade" explicita um processo no qual os produtos e os efeitos são ao mesmo tempo causas e produtores daquilo que os produziu. É ele que nos ajuda a romper com a ideia linear de causa $\rightarrow$ efeito, uma vez que o efeito retorna sobre a causa em um ciclo auto-ecoorganizador e produtor. Seria mais adequada a esquematização causa $\leftrightarrows$ efeito. Regido por este princípio, entendemos porque o amor pode manter a noção de regulação do processo, ampliada pela de auto-produção e auto-organização. A causa age sobre o efeito e o efeito age sobre a causa (MORIN, 2002), indicando mecanismos por meio dos quais todo sistema busca permanecer em equilíbrio dinâmico, ou seja, há fluxos de dispersão de energia e fluxos de captação de matéria, informação e energia do mundo externo e/ou de outros sistemas que o fazem manter-se "vivo". São fenômenos inflacionadores ou estabilizadores.

Em Oltramari (2009, p. 29-33) temos comentários importantes sobre o como se lê e se pensa o amor entre os clássicos. Segundo o autor, Goethe, por exemplo - poeta e escritor alemão do século XIX -, reconheceu que sem amor o sujeito não se completa, que ele deixou transparecer, em algumas de suas obras, que o amor é a forma mais radical de se reconhecer intimamente um ser humano diferente. Amar é, então, em certo sentido, negar a própria individualidade a fim de viver intensamente a aventura de mergulhar na alteridade e inserir-se, ativamente, no movimento da comunidade humana.

Esse movimento nos reporta ao "princípio holográfico", este princípio assegura que a parte náo somente está dentro do todo, como o próprio todo também está dentro das partes (MORIN, 200I). O princípio holográfico nos remete à articulação de pares binários: parte-todo, simples- 
complexo, local-global, unidade-diversidade, particular-universal, abrindo uma nova perspectiva, sobretudo aos professores, pois não se trata somente de inverter o foco do binário parte-todo, mas de acrescentar o movimento de religaçáo ao conjunto, à totalidade fragmentada. Entendemos que o amor necessita do contexto e da unidade simples (todo e parte) em interligação dinâmica.

Os três princípios - dialógico, recursivo e holográfico - são três expressóes da mesma ideia, pensar o amor a partir destes princípios propostos pela teoria da complexidade é buscar compreender que a totalidade que envolve a amorosidade não se resume apenas à justaposição de partes separadas, ou seja, nem a totalidade nem a parte são preponderantes uma sobre a outra, seus antagonismos, seus contrários, sua articulação representam partes que estáo em constante diálogo. Sem esse diálogo, o amor não existiria.

Konder (2007), autor de diversos artigos e livros, estudioso da filosofia marxista, nos surpreende com uma obra sobre o amor, não usual em seu currículo. Ele não se propôs conceituar o amor, mas trabalhá-lo a partir de diversos autores que vão de Platão e Sócrates a Simone de Beauvoir, e também os brasileiros Guimarães Rosa e Carlos Drummond de Andrade, explicitando suas trajetórias de vida, por vezes suas vidas amorosas e suas concepçóes de amor.

Durante a sua análise, à qual se propóe a discussão sobre o conceito filosófico do amor, Konder (2007) deixa claro que, apesar dos riscos, das vicissitudes do amor, ele (o amor) se faz uma experiência necessária e não, como muitas vezes pode ser descrita, uma perda no campo da humanidade. Ele ainda nos traz importante contribuição sobre o amor e os escritos de Marx; alega que, para Marx, "[...] o amor é uma 'maneira universal' que o ser humano tem de se apropriar do seu ser como 'um homem total', agindo e refletindo, sentindo e pensando, descobrindo-se, reconhecendose e inventando-se [...]" (KONDER, 2007, p. 2I). O amor, então, levaria as pessoas a se realizarem plenamente enquanto tais: seres senhores de si, de suas vidas, de seus destinos, e não criaturas completamente absorvidas pela lógica cega da realização do Capital. Konder indica a leitura do texto "Marx: os revolucionários também amam", para explicitar melhor o como os revolucionários amam. 
O sociólogo polonês Bauman (2004, p. 8), em "Amor líquido", debate sobre o amor articulando-o à fragilidade dos laços humanos. Traz uma reflexão crítica do cotidiano do homem moderno, ressaltando a importância do amor, e da dificuldade de amar o próximo nas sociedades modernas. $\mathrm{O}$ autor concebe o "cidadão de nossa líquida sociedade moderna”, um sujeito com dificuldades no estabelecimento de vínculos e, por isso mesmo, com dificuldades em expressar e viver o amor, o que o torna um ser imperfeito.

O pior é que Bauman enfatiza que o viver sem o outro faz com que o sujeito humano sinta a falta de si mesmo, e isso o faz pensar (e perceber) que suas frágeis relaçóes são sem perspectivas. Tal reflexão obriga-o a questionar sobre as possibilidades de se retornar ao amor, manifestando a ação do "princípio da autonomia/dependência".

Segundo Morin (2002), os seres vivos, os humanos e as sociedades são auto-organizadores e não param de se autoproduzirem, o que pressupôe seres auto-eco-organizadores. A partir do princípio da autonomia/ dependência, o conceito de autonomia é complementar ao de dependência e, ao mesmo tempo, antagônico. Segundo este princípio, o amor liga-se à ideia de autonomia que se constrói em termos relacionais e relativos, distanciando-se, portanto, de uma liberdade absoluta emancipada de qualquer dependência. $\mathrm{O}$ amor, assim como a autonomia do sujeito, promove o entendimento que ele é dependente do ambiente onde vive, de sua ascendência genética e da sociedade em que se inscreve.

Como destacou Rodhen (1997), o homem é a sua eterna potencialidade, isso significa que dentro de cada um de nós existe algo maior e melhor do que aquilo que existe fora de nós, que somos muito mais aquilo que podemos vir a ser e desejamos ser do que aquilo que somos no plano histórico da vida. Nessa mesma linha de raciocínio, Brandão (2005; 2008) sugere que isso se daria através do aprender o amor, porque o amor é um afeto que se ensina com uma educação que se preocupa com o humanizar.

Bauman (2004) destaca outro aspecto importante sobre o amor. Ele entende que o amor próprio é construído a partir do amor que nos é oferecido por outros, evidenciando que a construção de amar a si próprio, só pode ser manifestada a partir de outros, que devem nos amar primeiro para que comecemos a amar a nós mesmos. Então, formar pessoas tam- 
bém significa ensiná-las a viver e a amar e, como concebe Crema (20I0), também significa formar almas.

Drummond (1985), no campo dos poetas, mostra no seu livro Amar se aprende amando que esse "sentimento" deve ser entendido e vivido como uma prática, precedendo o que Brandão (2005), no campo da educação, iria abordar sobre o mesmo assunto décadas depois. Então, em ambos, temos que o amor pode ser ensinado e apreendido, cremos que isso deve interessar muito a educação.

Brandão (2005), em seu livro Aprender o amor, descreve pessoas criadoras de afetos e de ideias que pensam o ser humano sem degenerá-lo em objeto:

Ao pensar o ser humano e sua formação, por meio disso que chamamos, com uma imagem já tão agrícola, tão ambiental de educação ("fazer sair para fora", "ajudar a que saia de dentro da terra de um eu”), me dou conta de que é do amor que se trata (BRANDÂO, 2005, p. 27. Grifos do autor).

O amor pode, e necessita ser colocado no fluxo do diálogo entre as pessoas, portanto estar presente na arte do educar. Em se tratando de processos formativos, o "[...] obscurantismo nefasto causado por um saber crescentemente acumulativo e um ser interior cada vez mais empobrecido faz do religar conhecimento ao amor o mais instigante desafio do momento [...]" (CREMA, 20Io, p. 4).

O amor é uma forma de os humanos procurarem um mundo melhor. Isso é muito bem explicado por Piaget (1978) e com ele aprendemos que a aprendizagem de valores éticos e afetivos necessita de experiências de reciprocidades, interativas e pedagogicamente criadas para isso. Explicando melhor: assim como o amor, o valor da solidariedade só pode ser apreendido por aqueles que se reúnem para praticá-lo em alguma dimensão não regida por uma lei exterior e imposta, mas, ao contrário, por preceitos co-partipados de interação e reciprocidade que as pessoas criam.

Vejamos que na proposta de Magalhães

[...] uma disposição de caráter é resultado de um sistema de valores que vão se constituindo na pessoa a partir de suas re- 
laçóes com o seu contexto, consigo e com os outros; portanto, pelas trocas estabelecidas. Dessas trocas surgem sentimentos que lhe permitem sentir o mundo, a reação dos outros às suas açôes, às suas reaçôes a açôes dos outros [...] Do ponto de vista das relaçôes sociais que imperam em um sistema como o nosso, a ação solidária ou "ação amorosa" implica dar sentido, criar diferentes açôes com todos os sujeitos de nossa sociedade. Novas formas de ação não-indiferente a essas questóes pode promover nos sujeitos a solidariedade. É pelo amor que a solidariedade cresce no interior das pessoas; a solidariedade é um subvalor derivado da amorosidade. (MAGALHÁES, 2003, p. 24. Grifos nossos).

Por essa lógica, os valores éticos, estéticos, sensíveis e afetivos, derivam do amor, e precisam de pessoas e de contextos para serem apreendidos e ensinados, o que será, no final das contas, refletido nas relaçốes estabelecidas no social.

Reafirmando essas colocaçôes, em Adorno (2006), filósofo da Escola de Frankfurt, da ênfase ao papel da nossa sociedade no combate à barbárie, indicando que o fator principal a favor da desbarbarização é o amor. Segundo esse autor, o amor ao ser humano implica garantia do direito à existência do diferente. Ele afirmou: "[...] se não fosse pelo meu temor em ser interpretado equivocadamente como sentimental, eu diria que, para haver formação cultural, se requer amor [...]" (ADORNO apud BRANDÃO, 2005, p. I9).

Em Teilhard de Chardin (I995) temos que o amor é uma categoria essencial que expressa e explica os mistérios do fenômeno humano. Somente o amor pode indicar o caminho para a criação de sociedades com realização fecunda da experiência humana. A trajetória da espécie humana demonstra a presença do amor.

Com Teilhard de Chardin (1995) desvendamos que é a opção de escolher nossos caminhos por meio da adesão a princípios de amorosidade, de solidariedade, que nos conduzirá a uma humanidade livre e generosamente fraterna. A escolha do amor como único caminho, revelaria uma humanidade próxima do "Ponto Ômega", no qual a humanidade revela-se superior, com elevadas potências físico-morais. 
Morin (2003, p.70) também se manifesta sobre o amor, no livro Amor, poesia, sabedoria, no qual interroga três evidências presentes entre as pessoas: o amor, a poesia, a sabedoria, sendo que a sabedoria traz em si uma contradiçáo, pois, para ele, é louco viver muito sabiamente, por isso, devemos reconhecer que, na loucura que é o amor, há a sabedoria do amor. Com todos os perigos que carrega, o importante, na vida, é o amor porque nos faz viver em estado de enamoramento, regenerando-se a partir de si mesmo.

Bubber (1997), outro filósofo e escritor de origem austríaca, que marcou sua obra por uma constante e incansável procura do sentido do humano, a fim de resgatar a dignidade da responsabilidade que lhe é inerente na construção de um mundo humanizado, elegeu a relação dialógica como o ponto de partida para a procura do sentido da existência humana, e, em termos práticos, para a construção de uma comunidade onde o princípio ético, ao lado do princípio político, encontre o lugar de sua realização. Entendemos que essa é uma experiência que só é possível com o outro, no encontro fecundado e no diálogo.

Bubber (1997) declara a importância da relação com o outro para que ocorra a humanização, pois o homem é um ser de relaçôes, que pode estabelecer uma relação essencial e recíproca, direta e gratuita, mas ela só pode acontecer no amor.

Essas discussões sobre o amor delineiam que a experiência amorosa pode ser vivida como uma experiência do sagrado. $\mathrm{O}$ significado do sagrado é discutido por Nicolescu (I999), em seu livro "O manifesto da transdisciplinaridade", no qual refere-se a um fenômeno especial de interação, intercâmbio e de comunicação. Algo realmente transdisciplinar que atravessa, que vai além, movimento ascendente e descendente de informaçóes e da consciência, transpondo os diferentes níveis de realidade e de percepção. O sagrado seria, então, o transcendente e transdisciplinar, aquele que cria uma comunicação contínua, um diálogo permanente, sem resistência entre a pessoa e o mundo.

No contexto da formação, entender o amor como experiência do sagrado seria manifestar uma interação respeitosa e verdadeiramente inclusiva da diversidade de saberes, o que facilitaria a construçáo das relaçôes entre diferentes. Manifesta-se, assim, o "princípio da reintroduçáo do conhecimento". 
Este princípio indica que tudo se liga a tudo, reciprocamente, numa rede relacional e interdependente, nada pode permanecer ou estar isolado no cosmos, mas sempre em relação a algo. Assim pensado, por causa do que promove no ser humano, o amor pode auxiliar na religaçáo dos saberes e promover a superação dos perigos do saber instrumental e de suas consequências para a atuação docente.

A presença do amor, ou do sagrado, pode criar um "saber sapiente" capaz de confrontar nossos valores, ideais, convicçôes, crenças, permitindo que os sujeitos transitem em diferentes dimensóes, dialogando, sem pré conceituar ou rotular, mas interagindo na dinâmica de renovar-se e recriar-se, sempre numa postura aberta, disponível a acrescentar o novo, o transgredir, na composição de uma consciência planetária e afetiva.

Indo de encontro ao pensamento de Nicolescu (1999), o sagrado promove um exemplo de afinidade que necessita ser reconhecido e valorizado como padrão que une, que faz com que as relaçóes transitem com fluidez, sem resistência, acolhidas por um padrão de afinidades exercidas com "abertura" para interagir com o novo. E ainda, com "rigor" para construir o domínio de comunicação dos grupos, e com "tolerância” para reconhecer a diversidade como valor necessário à dinâmica da existência e da vivência da realidade, o que tornará cada professor capaz de estabelecer a união entre a ciência e a consciência.

Esta vivência amorosa pode irromper valores do respeito, da bondade, da fraternidade, da solidariedade, da inclusividade (CREMA, 20Io). A ideia central é que a "[...] emoção fundamental que torna possível a história da hominização é o amor [...]”. A experiência amorosa transforma, é autopoiética (MATURANA; VARELA, I995, p. 217).

Retomemos Freire (2000) quando diz que só um homem transformado é capaz de transformar, com autonomia e responsabilidade ele ascende à emancipaçáa. Ao compartirmos amorosamente estaremos compartindo regras sociais amorosas que estabelecerão simbólica e significativamente que tipos de relacionamentos queremos incentivar em nossa sociedade.

O importante é que o homem sente-se concreto, vivo, numa relação com o outro, em diálogo verdadeiro na presença de uma relação amorosa. Pesquisar, refletir, falar sobre o amor e sua importância para a vida e para a formação docente, não é uma conversa acabada. Por enquanto, estes autores nos ajudaram compreender que o amor representa uma estranha força 
que tende a reaparecer com todo entusiasmo quando cogitamos a possibilidade de humanizar o infra-humano (ARRUDA, 2003; 2006).

$\mathrm{O}$ valor do amor nos mostra que o transdisciplinar exige a emergência do que há na alma humana. Ademais, nossa natureza humana nos impele ao amor, pois "[...] sem amor, sem a aceitação do outro, não há fenômeno social [...]” (MATURANA; VARELA, I995, p. 264).

O amor é a fonte da socialização humana [...] qualquer coisa que destrói o amor, qualquer coisa que destrói a congruência estrutural que ele implica, destrói a socialização. A socialização é o resultado do operar no amor, e ocorre somente no domínio em que o amor ocorre (MATURANA, 1997, p. I85).

Para finalizar, reafirmo, com o apoio de Brandão (2005), que a educação necessita recuperar os campos da vivência do amor: amorosidade, gratuidade, generosidade, partilha, caridade dos cristãos, saber cuidar, compaixão dos budistas, solidariedade, cooperação, criatividade, co-responsabilidade e liberdade, reconfigurando sentidos subjetivos (GONZÁLEZ REY, 2003), a partir dos quais, é possível mudar sujeitos pensantes, bem como às emoçóes produzidas em diferentes situaçóes de ensino-aprendizagem.

Somos seres pertencentes à solidariedade e à cooperação, não ao interesse egoísta e à competição. Somos destinados ao encontro solidário entre sujeitos, e não à agressáo [...] tudo o que não é amor em nós não é nosso outro lado. Tudo o que o amor nâo acende e clareia em nós não é o nosso lado de sombra. É a ausência do que originalmente é nosso em nós mesmos: é a nossa doença. É o desvio do rumo do caminho que somos destinados a ser e a percorrer. Tanto é assim que adoecemos, interior e interativamente, quando somos obrigados a conviver em contextos de relaçóes com nossos outros, onde o afeto da emoção do amor não rege o que está acontecendo. E, assim, onde a emoçáo do amor náo dirige o que estamos criando [...] o que fazemos nos torna enfermos. Sem a experiência da vivência cotidiana do amor não vivemos apenas mal: no correr 
do tempo, nós não sobrevivemos (BRANDÃO, 2007, p. I50. Grifos nossos).

O que é especialmente humano no amor, não é o amor, mas o que fazemos no amor enquanto humanos. Com ele é possível superar a idéia de que o "ser sujeito humanizado" não é apenas ser consciente-afetivo, mas tão somente pressupor sua integração e seu caráter multidimensional, entendendo que ele, assim como todo o cosmo, se liga a tudo, reciprocamente, numa rede relacional e interdependente. Ao mesmo tempo em que o indivíduo é autônomo, é dependente amorosamente do(s) outro(s)constrói novos sentidos subjetivos, numa circularidade que o singulariza e distingue simultaneamente. Afinal, ele está junto, é tecido junto (MORIN, 200I).

\section{Referências}

ADORNO, T. Educação e emancipação. Paz e Terra: São Paulo, 2006.

ARRUDA, M. Humanizar o infra-humano: A formação integral do ser humano Homo Evolutivo, Práxis e Economia Solidária. Petrópolis: Editora Vozes, 2003. 
CREMA, R. Inteligência integral. Revista Sophia, ano 8, n. 29, jan.-mar. 20 Io.

DELORS, J. Educação: um tesouro a descobrir. São Paulo: Cortez, 2000.

DRUMMOND A. C. Amar se aprende amando. Rio de Janeiro: Record, I985.

FREIRE, P. Pedagogia da autonomia: saberes necessários à prática educativa. I5. ed. São Paulo: Paz e Terra, 2000.

GANDHI, M. The Gandhi reader. Bloomington: Indiana University Press, 1956.

GONZÁLEZ REY, F. Sujeito e subjetividade: uma aproximação histórico-cultural. São Paulo: Pioneira Thompson, 2003.

- Pesquisa Qualitativa e subjetividade: os processos de construção da informação. São Paulo: Pioneira Thomson Learning, 2005.

. Questóes teóricas e metodológicas nas pesquisas sobre a aprendizagem. A pesquisa no nível superior. Em MARTÍNEZ, A. M. E TACCA, M. C. V. R. (orgs). A Complexidade da aprendizagem destaque ao ensino superior. Campinas, SP: Editora Alínea, 2009.

KONDER, L. Sobre o amor. São Paulo: Boitempo, 2007.

MAGALHÃES, S. M. O. Do sagrado ao vivido: a educação do sentimento. Goiânia: anotaçóes de aula, Xerox, 2003.

MATURANA, H. Reflexões sobre o amor. In: MAGRO, C.; GRACIANO, M.; VAZ, N. (Org.). A ontologia da realidade. Belo Horizonte: UFMG, I997.

MATURANA, H.; REZEPKA, S. N. Formação humana e capacitação. Petrópolis: Vozes, 2000.

_; VARELA, J. A árvore do conhecimento. Campinas: PSY, I995.

. Reflexôes sobre o amor. In: MAGRO, C.; GRACIANO, M.; VAZ, N. (Org.).

A ontologia da realidade. Belo Horizonte: UFMG, 1997.

MORAES, M. C. O paradigma educacional emergente. 4. ed. Campinas: Papirus, I997.

MORIN, E. Introdução ao pensamento complexo. 3. ed. Lisboa: Instituto Piaget, 200I. I77p. . A cabeça bem feita: repensar a reforma, reformar o pensamento. 7. ed. Rio de

Janeiro: Bertrand do Brasil, 2002.

Amor, poesia, sabedoria. Rio de Janeiro: Bertrand Brasil, 2003.

. Os sete saberes necessários à educação do futuro. São Paulo: Cortez; Brasília, DF:

UNESCO, 2007.

NICOLESCU, B. O manifesto da transdisciplinaridade. São Paulo: Triom, I999. 
OLTRAMARI, L. C. Ler o amor, pensar o amor. Estud. pesqui. psicol. [online]. v. 9, n. 2, set. 2009. Disponível em: <http://pepsic.bvs-psi.org.br/scielo.php?script=sci_ arttext\&pid=SI808-428I 20090002000 I9 \&lng=pt\&nrm=iso $>$. ISSN I808-428I. Acesso em: 22 jan. 2910.

PIAGET, J. Para onde vai a educação? Rio de Janeiro: José Olympo, I978.

ROHDEN, H. Novos rumos para a educação: ocaso de uma ideologia decrépita.

Alvorada de uma filosofia dinâmica. São Paulo: Martin Claret, I997.

TEILHARD DE CHARDIN, P. O fenômeno humano. Tradução de José Luiz Archanjo. São Paulo: Cultrix, I995.

SCOZ, B. J. L. Aprendizagem e ensino de professores sentidos subjetivos. Em MARTÍNEZ, A. M. E TACCA, M. C. V. R. (orgs). A Complexidade da aprendizagem destaque ao ensino superior. Campinas, SP: Editora Alínea, 2009.

VEIGA, I. P. A. A prática pedagógica do professor de didática. Campinas: Papirus, 1989.

Recebido em 23 set. 2010 / Aprovado em I8 fev. 2012

Para referenciar este texto

MAGALHÃES, S. M. O. A formação de sentidos subjetivos potencializadores da amorosidade no espaço educacional. EccoS, São Paulo, n. 27, p. I45-I62. jan./abr. 20 I2. 